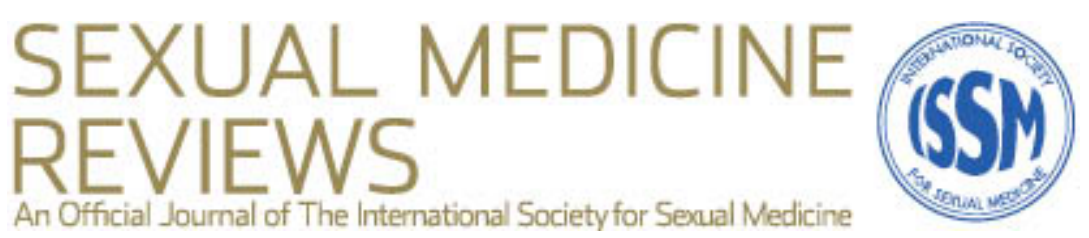

\title{
Testosterone therapy: An assessment of the clinical consequences of changes in haematocrit and blood flow characteristics
}

\begin{tabular}{|c|c|}
\hline Journal: & Sexual Medicine Reviews \\
\hline Manuscript ID & SMR-11-2018-070.R2 \\
\hline Aritcle type: & Review \\
\hline Keywords: & $\begin{array}{l}\text { Late onset testosterone deficiency, Testosterone therapy, Haematocrit, } \\
\text { Type } 2 \text { Diabetes, blood viscosity, microvascular flow }\end{array}$ \\
\hline Subject Area: & $\begin{array}{l}\text { Risk factors/co-morbidities < BASIC SCIENCE }<\text { MALE, Sex steroid } \\
\text { replacement }<\text { TREATMENT }<\text { MALE }\end{array}$ \\
\hline Abstract: & $\begin{array}{l}\text { Introduction. Clinical guidelines indicate that haematocrit should be } \\
\text { monitored during testosterone replacement therapy (TTh) with action } \\
\text { taken if a level of } 0.54 \text { is exceeded. } \\
\text { Aim. To consider the extent of changes in haematocrit and putative } \\
\text { effects on viscosity, blood flow and mortality following TTh. } \\
\text { Methods. We focused on literature describing benefits and possible } \\
\text { pitfalls of TTh including increased haematocrit. We used data from the } \\
\text { BLAST RCT to determine change in haematocrit after } 30 \text { weeks of TTh } \\
\text { and describe a clinical case showing the need for monitoring. We } \\
\text { consider the validity of the current haematocrit cut-off value at which } \\
\text { TTh may be modified. Ways in which haematocrit alters blood flow in the } \\
\text { micro- and macro-vasculature are also considered. } \\
\text { Main Outcome Measures. (1) change in haematocrit, (2) corresponding } \\
\text { actions taken in clinical practice and (3) possible blood flow changes } \\
\text { following change in haematocrit. } \\
\text { Results. Analysis of data from the BLAST RCT showed a significant } \\
\text { increase in mean haematocrit of } 0.01 \text {, the increase greater in men with } \\
\text { lower baseline values. While, none of } 61 \text { men given TTh breached the } \\
\text { suggested cut-off of } 0.54 \text { after } 30 \text { weeks, a clinical case demonstrates } \\
\text { the need to monitor haematocrit. An association between haematocrit } \\
\text { and morbidity and mortality appears likely but not proven and, may be } \\
\text { evident only in patient subgroups. The consequences of an increased } \\
\text { haematocrit may be mediated by alterations in blood viscosity, oxygen } \\
\text { delivery and flow. Their relative impact may vary in different vascular } \\
\text { beds. } \\
\text { Conclusions. TTh can effect an increased haematocrit via poorly } \\
\text { understood mechanisms and may have harmful effects on blood flow } \\
\text { that differ in patient subgroups. At present, there appears no scientific } \\
\text { basis for using an haematocrit of } 0.54 \text { to modify TTh; other values may } \\
\text { be more appropriate in particular patient groups. }\end{array}$ \\
\hline
\end{tabular}




\section{SCHOLARONE" Manuscripts}




\begin{abstract}
.
Introduction. Clinical guidelines indicate that haematocrit should be monitored during testosterone replacement therapy (TTh) with action taken if a level of 0.54 is exceeded.
\end{abstract}

Aim. To consider the extent of changes in haematocrit and putative effects on viscosity, blood flow and mortality following TTh.

Methods. We focused on literature describing benefits and possible pitfalls of TTh including increased haematocrit. We used data from the BLAST RCT to determine change in haematocrit after 30 weeks of TTh and describe a clinical case showing the need for monitoring. We consider the validity of the current haematocrit cut-off value at which TTh may be modified. Ways in which haematocrit alters blood flow in the micro- and macro-vasculature are also considered.

Main Outcome Measures. (1) change in haematocrit, (2) corresponding actions taken in clinical practice and (3) possible blood flow changes following change in haematocrit.

Results. Analysis of data from the BLAST RCT showed a significant increase in mean haematocrit of 0.01 , the increase greater in men with lower baseline values. While, none of 61 men given TTh breached the suggested cut-off of 0.54 after 30 weeks, a clinical case demonstrates the need to monitor haematocrit. An association between haematocrit and morbidity and mortality appears likely but not proven and ; may be evident only in patient subgroups. The consequences of an increased haematocrit may be mediated by alterations in blood viscosity, oxygen delivery and flow. Their relative impact may vary in different vascular beds.

Conclusions. TTh can effect an increased haematocrit via poorly understood mechanisms and may have harmful effects on blood flow that differ in patient 
subgroups. At present, there appears no scientific basis for using a haematocrit of 0.54 to modify TTh; other values may be more appropriate in particular patient groups. 


\section{Introduction}

Use of testosterone therapy (TTh) is increasing rapidly worldwide. For example, in the United States the cost of TTh in 2013 was $\$ 2.4$ billion with an expected increase to $\$ 3.8$ billion in 2018 (https://www.statista.com/statistics/320301/predicted-annualtestosterone-drug-revenues-in-the-us/ - accessed on 01/11/2018). Though the benefits of TTh in terms of reduced risk of cardiovascular disease (CVD) and mortality are reported in an increasing number of studies, some reports present a contrary view. This review is in two sections; the first considers the merits of TTh in men with low serum testosterone and associations between increased haematocrit, a well recognised adverse effect of the therapy, and morbidity / mortality. The second part considers the association between haematocrit and blood flow and discusses putative mechanisms whereby TTh may lead to development of pathology. Our approach has been to review the literature and present unpublished data from our BLAST randomised controlled trial that describes the relationship between TTh, increased haematocrit, morbidity and mortality. The importance of monitoring haematocrit is emphasised in a case report showing TTh leading to a markedly increased haematocrit requiring phlebotomy and replacement of injectable TTh with a gel formulation. We also speculate on the effect that increased numbers of red cells could have on blood flow characteristics in different vascular beds. The review is based on publications from basic science, longitudinal and randomised controlled trials and reviews known to us or selected from Pubmed (US National Library of Medicine).

\section{Testosterone Deficiency.}

Testosterone deficiency (TD), characterised by low testosterone levels and related symptoms, occurs in $6-12 \%$ of men $[1,2]$. TD is associated with decreased bone 
mineral density, lean mass, muscle strength, cognitive function, sexual function and increased fat mass $[1,2,3]$. The phenotype is categorised as primary TD, secondary TD (pituitary/hypothalamic disease) or adult onset TD. Adult onset TD describes in men older than 50 years (following exclusion of hypothalamic-pituitary-testicular axis pathology), a combination of low serum testosterone levels and accompanying symptoms The condition is associated with obesity, type 2 diabetes (T2DM) and the metabolic syndrome (MetS) $[3,4]$. Prevalence of adult onset TD in men with T2DM is about $40 \%[5,6]$. Indeed, low testosterone levels are associated with the number and severity of components classifying the metabolic syndrome (increased waist circumference / body mass index, glycaemia, triglycerides, blood pressure and decreased high density lipoprotein cholesterol) and ; may also predict the onset of diabetes in younger men [7].

Importantly, adult onset TD is associated with increased morbidity and mortality [4]. For example, the European Male Ageing study, (2599 men, (77\% withT2DM, aged 4079 years, about 4 years follow-up) showed the combination of TD symptoms and total testosterone $<8 \mathrm{nmol} / /(230.5 \mathrm{ng} / \mathrm{dl})$ was significantly associated with increased total and CVD mortality [7]. Importantly, there is also accumulating evidence from longitudinal observational studies that TTh can lead to improved sexual health and reduced all-cause mortality [4]. Shores et al studied the impact of TTh on mortality in 1031 males (aged over 40 years, total testosterone $\leq 8.7 \mathrm{nmol} / \mathrm{l}(250.7 \mathrm{ng} / \mathrm{dl})$, mean follow-up about 4 years), mortality in 398 men on TTh was 10.3\%), compared with untreated controls (20.7\%) [9]. Survival analysis showed significantly reduced mortality in men with T2DM but not in their non-diabetic counterparts. This finding was confirmed by 2 longitudinal studies of men with T2DM. Muraleedaran et al studied over 6 years, the effects of low testosterone (the cohort stratified by total 
testosterone of $10.4 \mathrm{nmol} / \mathrm{l}(299.7 \mathrm{ng} / \mathrm{dl}))$ and TTh on mortality in 581 men with T2DM [10]. Mortality was higher in 238 men with low testosterone (HR: 2.02, 95\% Cl: 1.2 3.4) compared to those with values above $10.4 \mathrm{nmol} / \mathrm{l}(299.7 \mathrm{ng} / \mathrm{dl})$ after adjustment for confounders. In the low testosterone group, the 174 men not on TTh were at significantly higher risk of mortality (HR: 2.3, 95\% Cl: $1.3-3.9$ ) than the 64 men receiving TTh. A longitudinal study in 857 men with T2DM by our group showed similar results [11]. We stratified the cohort using a total testosterone cut-off of 12.0 $\mathrm{nmol} / \mathrm{l}(345.8 \mathrm{ng} / \mathrm{dl})$ and free testosterone of $0.25 \mathrm{nmol} / \mathrm{l}(7.2 \mathrm{ng} / \mathrm{dl})$; over a mean 3.8 years, mortality was reduced in men on TTh with greatest benefit in older men $[11,12]$. Survival analysis (adjusted for age, phosphodiesterase 5-inhibitor and statin treatment) showed that compared with men with low testosterone (either low total or calculated free testosterone) not on TTh, mortality was lower in men with normal testosterone (HR: $0.62, \mathrm{Cl}: 0.41-0.94)$ and men with low testosterone on TTh $(\mathrm{HR}$ : $0.38, \mathrm{Cl}: 0.16-0.90)$. This benefit was independent of changes in conventional cardiovascular/metabolic risk factors (weight, body mass index, dyslipidaemia, glycaemic control, blood pressure) [13]. Further, Snyder et al. in the Testosterone trial, showed significant benefits in sexual function, mood, depression, quality of life, physical performance, vitality, anaemia and bone mineral density in the overall group, although this benefit was not evident in the individual studies [14]. The BLAST randomised controlled study suggested improvements in erectile dysfunction following TTh, especially in men with total testosterone levels $<8 \mathrm{nmol} / /$; the change reaching statistical significance only after 6 months of therapy $[15,16]$ with improvement continuing even after 4 years [17].

The above data provides the basis for the British Society for Sexual Medicine [4] and International Society for Sexual Medicine guidelines 
(https://professionals.issm.info/wp-content/uploads/sites/2/2018/05/ISSM-QuickReference-Guide-on-TD.pdf - accessed on 02/01/2019) that include the following management recommendations;

- Total testosterone $<8 \mathrm{nmol} / \mathrm{l}(230.5 \mathrm{ng} / \mathrm{dl})$ or free testosterone $<0.180 \mathrm{nmol} / \mathrm{l}$ (5.2ng/dl): usually requires TTh.

- Total testosterone $>12 \mathrm{nmol} / \mathrm{l}(345.8 \mathrm{ng} / \mathrm{dl})$ or free testosterone $>0.225 \mathrm{nmol} / \mathrm{l}$ (6.5ng/dl) : does not require TTh.

- Total testosterone $8-12 \mathrm{nmol} / \mathrm{l}(230.5-345.8 \mathrm{ng} / \mathrm{dl})$ may require a trial of TTh for a minimum of 6 months depending on symptoms.

\section{Possible cardiovascular adverse effects associated with TTh.}

Concern continues to exist (https://www.fda.gov/Drugs/DrugSafety/ucm436259.htm accessed on $02 / 01 / 2019)$

(http://www.ema.europa.eu/docs/en_GB/document_library/Referrals_document/Test osterone_31/Recommendation_provided_by_Pharmacovigilance_Risk_Assessment _Committee/WC500175213.pdf - accessed on 02/01/2019 ) regarding the cardiovascular safety of TTh in the treatment of adult onset TD. Thus, while most studies demonstrate either benefit or no increase in cardiovascular events, a few widely cited studies have reported increased CVD in patients on TTh $[18,19]$. Vigen et al used a composite of all-cause mortality, myocardial infarction and stroke rates as outcome in patients with low testosterone levels who had undergone coronary angiography and subsequently received TTh [20]. Though the event rate was $10.1 \%$ in testosterone treated and $21.2 \%$ in untreated patients, after adjustment for over 50 variables (baseline testosterone and erectile dysfunction, both associated with allcause mortality were not included), TTh appeared associated with increased events 
(25.7\% in treated, $19.9 \%$ in untreated groups) during 3 years follow-up. Finkle et al examined 55,593 insurance claims and compared the incidence rate of myocardial infarction in the 12 months prior and 3 months after the initial prescription of TTh and reported an increased rate of non-fatal myocardial infarctions especially in men aged 65 years or older [21]. In younger men, the risk was confined to those with preexisting heart disease. Importantly the control group was comprised of men commenced on phosphodiesterase 5-inhibitors which have been demonstrated to lower cardiovascular and all-cause mortality $[11,12,22,23]$. Further, there were design flaws including lack of data on testosterone levels, the reporting of only nonfatal events and a retrospective review of the previous 12 months only after the decision on TTh was made. Three months follow up may be insufficient to detect benefit from TTh and the authors conceded that increased events could be related to TD rather than TTh. Basaria et al published the 'Testosterone in Older men with Mobility Limitations (TOM) Trial' of 209 older men (mean age: 74 years) with limited mobility randomised to either testosterone or placebo gel [24]. Though the primary outcome (change in maximal voluntary muscle strength during leg press exercise) was met, the trial was discontinued as 23 men given TTh and 5 men given placebo appeared to develop cardiovascular related adverse events. However, in addition to the limitations imposed by a relative small cohort there was no cardiovascular assessment at baseline and events were based on self reporting and included a wide range of symptoms including peripheral oedema and syncope. Though these studies have flaws and the mechanism for the putative adverse effect of TTh is unidentified, they do indicate a need to better assess potential problems in using TTh especially in patient subgroups. 
We recently speculated on the effects that patient heterogeneity could have on treatment benefits [25]. For example, a small patient subgroup may be at an increased risk that cannot be detected in large trials with wide inclusion criteria. Accordingly, clinical outcomes associated with TTh need to be identified using randomised controlled trials and observational longitudinal studies that evaluate benefits and adverse effects in the total cohort and subgroups.

\section{Increased haematocrit following TTh}

In this context, the effects of TTh on haematocrit and potentially clinical outcome are important. Thus, an increase in haematocrit is the commonest adverse effect linked with TTh $[26,27,28]$ with values $>0.54$ used to alter dose or discontinue treatment $[4]$.

The need for regular monitoring of haematocrit is exemplified in a case report. Patient MM, a male aged 53 years was referred to the metabolic clinic at University Hospitals Birmingham NHS Foundation Trust in 2007 with severe fatigue, erectile dysfunction and the MetS. He was diagnosed with T2DM in 2012 with a total testosterone of $3.6 \mathrm{nmol} / \mathrm{l}(103.7 \mathrm{ng} / \mathrm{dl}), \mathrm{LH}: 0.6 \mathrm{IU} / \mathrm{l}, \mathrm{FSH}: 3.6 \mathrm{IU} / \mathrm{l})$ and similar values on repeat testing (fasting sample at 9 AM). Other biochemical investigations including a $\mathrm{GnRH}$ dynamic function test were unremarkable. A diagnosis of adult onset TD was made and he was commenced on testosterone gel $(2 \%)$ with 4 applications/day (each application 10mg testosterone) with haematocrit levels $<0.54$ $(0.499-0.536)$ until November 2016 (total testosterone: $6.9 \mathrm{nmol} / \mathrm{l}(198.8 \mathrm{ng} / \mathrm{dl})$, calculated free testosterone: $0.14 \mathrm{nmol} / \mathrm{l}(4.0 \mathrm{ng} / \mathrm{dl}))$. When the testosterone gel was increased to 5 daily applications in view of persisting symptoms, the haematocrit increased to 0.565 (total testosterone: $12.0 \mathrm{nmol} / \mathrm{l}(345.8 \mathrm{ng} / \mathrm{dl})$, calculated free testosterone: $0.24 \mathrm{nmol} / \mathrm{l}(6.9 \mathrm{ng} / \mathrm{dl}))$. TTh was reduced to 4 applications daily and in 
view of increasing fatigue levels the patient was referred to the Urology clinic in January 2017 and testosterone undecanoate injections were commenced in March 2017. Energy levels improved with this therapy and in June 2017 total testosterone was $13.3 \mathrm{nmol} / \mathrm{l}(383.3 \mathrm{ng} / \mathrm{dl})$, calculated free testosterone was $0.25 \mathrm{nmol} / \mathrm{l}(7.2 \mathrm{ng} / \mathrm{dl})$ and haematocrit was 0.536 . The haematocrit had significantly increased at review in December 2017; thus, six weeks after testosterone undecanoate administration, total testosterone: $28.8 \mathrm{nmol} / /(830.0 \mathrm{ng} / \mathrm{dl})$, calculated free testosterone $0.70 \mathrm{nmol} / \mathrm{l}$ $(20.2 \mathrm{ng} / \mathrm{dl})$ and haematocrit 0.638 . The testosterone undecanoate was immediately discontinued and the patient commenced on aspirin. A check after 3 weeks showed the haematocrit was 0.648 , serum total testosterone was $26.8 \mathrm{nmol} / \mathrm{l}(772.3 \mathrm{ng} / \mathrm{dl})$ and calculated free testosterone was $0.65 \mathrm{nmol} / \mathrm{l}(18.7 \mathrm{ng} / \mathrm{dl})$. The patient underwent immediate venesection and the haematocrit gradually reduced; January 2018: 0.557, February 2018: 0.544, April 2018: 0.537, July 2018: 0.530. In August 2018 the haematocrit was 0.499 with total testosterone of $3.7 \mathrm{nmol} / /(106.6 \mathrm{ng} / \mathrm{dl})$ and calculated free testosterone of $0.08 \mathrm{nmol} / /(2.3 \mathrm{ng} / \mathrm{dl})$. The patient was suffering severe fatigue and erectile dysfunction and wished to restart testosterone gel. At the last follow-up in August 2018 (on 4 gel applications) the haematocrit was 0.507 , total testosterone $15.4 \mathrm{nmol} / \mathrm{l}(443.8 \mathrm{ng} / \mathrm{dl})$ and calculated free testosterone $0.41 \mathrm{nmol} / \mathrm{l}$ (11.8ng/dl) with some clinical improvement.

The patient's written consent allowing us to describe this case was obtained and filed in his hospital notes. It emphasises the need for monitoring and appropriate action where needed. As recommended by guidelines, we used a haematocrit of 0.54 as threshold for reducing or stopping TTh [4]. This level appears based on the haematocrit reference range and not on evidence. Clearly, given data linking elevated haematocrit levels with increased morbidity/mortality, an evidence-based 
threshold value that can be used in clinical practice is needed. A further issue in using TTh may be the testosterone preparation and its mode of delivery [28]. A recent comprehensive review suggested short-acting, injectable testosterone is associated with greater risk of elevated haematocrit compared with other preparations [28]. This raises the possibility that the rate of change in serum testosterone concentration may be mechanistically important; short-acting injectable testosterone could lead to steeper rises and falls in hormone levels that in turn has effects on erthrocytosis. However, as demonstrated by the above case, monitoring of haematocrit is needed with all testosterone preparations including long-acting injectable TTh.

\section{Change in haematocrit after 30 weeks TTh in the BLAST study}

The BLAST randomised controlled trial (European Union Clinical Trials Register: EudraCT 2008-000931-16) comprised a 30 week randomised double-blind placebocontrolled multicentre study carried out during September 2008 - June 2012 to assess the impact of TTh using testosterone undecanoate, a long-acting injectable preparation in 199 men with T2DM (primary outcome: change in glycaemic control) [29]. Baseline and final visit haematocrit data were available in 134 (placebo: 73 men, TTh: 61 men) of the 189 men completing the study (placebo: 103 men, TTh: 86 men). No significant change in haematocrit was observed in the placebo group (baseline: 0.432 , final visit: $0.435, p$ (paired $t$-test) $=0.22$ ). The haematocrit increased significantly in the TTh group (baseline: 0.444, final visit: 0.454, p (paired t-test $)=0.01)$ but did not breach the 0.54 threshold in any patient during 30 weeks of treatment.

Haematocrit at baseline was only associated with diastolic blood pressure (linear regression, coefficient $(\mathrm{c}): 0.11,95 \% \mathrm{Cl}: 0.06-0.17, \mathrm{p}<0.001)$. When adjusted for 
baseline age, total testosterone and other classifying characteristics of the MetS (body mass index, triglycerides, HDL-cholesterol, HBA1c, systolic blood pressure), this association remained significant (multiple regression, c: $0.07,95 \% \mathrm{Cl}: 0.006$ $0.14, p=0.03$ ). Only baseline haematocrit (not age, total / free testosterone level or metabolic parameters) was associated with the 0.010 increase in haematocrit in men on TTh (c: $-0.35,95 \% \mathrm{Cl}:-0.56--0.14, p=0.001)$. The finding that the coefficient had a negative value indicates reassuringly, that lower not higher baseline haematocrit levels were associated with the largest increases. No such association was observed in the placebo group (c: $-0.11,95 \% \mathrm{Cl}:-0.29-0.07, p=0.22)$. Figure 1 illustrates the change in haematocrit following 30 weeks of treatment with placebo or TTh. The negative coefficient observed between baseline and change in haematocrit in the BLAST patients differs from data reported by Ip et al who showed higher trough testosterone levels predicted an increased haematocrit $>0.50$ [30].

The mechanism for increased haematocrit following TTh is unclear. Coviello et al demonstrated a linear dose-dependent increase in haemoglobin and haematocrit levels following TTh, this observed in both 60 men aged 60 - 75 years and 61 men aged 19 - 35 years. However, the increase was more evident in the older men [31]. Interestingly, we observed greater reductions in mortality following TTh in older men $[11,12]$. No increase in erythropoietin or the marker of bone marrow erythropoetic activity, soluble transferrin receptor, was noted. They speculated androgens may have a direct stimulatory effect on the bone marrow and perhaps promote differentiation of erythroid colony forming units into erythropoietin sensitive cells. In contrast Bachman et al found that an increase in haemoglobin and haematocrit was associated with elevated erythropoietin levels 1-3 months following TTh, but the 
levels returned to normal after 6 months [32]. Despite increased haemoglobin and haematocrit, erythropoietin levels were not suppressed.

\section{Elevated haematocrit and increased morbidity / mortality}

We now consider longitudinal observational studies that evaluate the association between haematocrit and CVD. While no consensus has been reached, there are hints of a non-linear relationship. In a meta-analysis of 16 population-based prospective studies comprising 8020 individuals (mean haematocrit $=0.440$ ), Danesh et al showed the top tertile of haematocrit (haematocrit $>0.463$ ) was associated with increased coronary heart disease (risk ratio: 1.16, 95\% Cl: $1.05-$ 1.29) compared to the bottom tertile (haematocrit < 0.417) [33]. Addition of another 3 trials comprising individuals with established cardiovascular disease strengthened the above association between the 2 extreme tertiles (risk ratio: $1.81,95 \% \mathrm{Cl}: 1.19-$ 2.76). However, the authors urged caution as adjustment for other coronary heart disease risk factors which were associated with haematocrit levels, varied between the trials.

These findings were not confirmed by the European Prospective Investigation into Cancer and Nutrition - Netherlands (EPIC-NL) study (derived from the MORGENEPIC and Prospect-EPIC studies) comprising 16,187 individuals without CVD at baseline [34]. No association was found between the haematocrit tertiles (cut-off values 0.45 and 0.47 ) and 10 year risk of CVD, strokes and coronary heart disease. The Scottish Heart Health Extended Cohort Study estimated the predictive value of plasma viscosity, haematocrit and whole blood viscosity (dependent on plasma viscosity and haematocrit) for cardiovascular events in 3386 men and women aged $30-74$ years followed up for $10-21$ years [35]. High plasma viscosity was independently associated with CVD events and mortality. Although haematocrit 
(mean \pm SD: $0.4381 \pm 0.0394$ ) was significantly associated with CVD events (HR: 1.14, 95\% Cl: $1.04-1.25, \mathrm{p}=0.004)$ and mortality (HR: 1.22, 95\% Cl: $1.11-1.33$, $p<0.001$ ) when adjusted only for age and gender, significance was lost when confounders such as lipids, blood pressure, diabetes, smoking status, family history of CVD and fibrinogen were included.

A 34 year follow-up of 5209 men and women from the Framingham cohort indicated that the highest haematocrit quintile was associated with increased CVD and allcause mortality [36]. A dual effect was hinted at with a $\mathrm{J}$ or $\mathrm{U}$ shaped relationship between haematocrit and cardiovascular events. Further evidence for a non-linear association was added by Boffetta et al; in a study of 49,983 Iranian adults, a Ushaped relationship between categories of haematocrit and mortality was found in both sexes, with both low and high values associated with increased overall mortality [37]. In males, compared to the reference group (haematocrit 0.40-0.44), all-cause mortality and mortality related to CVD were increased when the haematocrit was either below 0.39 or above 0.45 (adjusted Cox regression), whilst in females compared to the reference group (0.35-0.40), all-cause mortality was greater when haematocrit was below 0.35 or above 0.40 and mortality related to CVD greater when haematocrit was below 0.30 or above 0.40 .

Locatelli et al studied the effects of erythropoietin in 5302 patients with end stage renal disease (mean baseline haematocrit \pm SD: $0.301 \pm 0.045$ ) on the Lombardy Registry [38]. It was evident that all-cause mortality risk was inversely proportional to the increase in haematocrit (OR: $0.95,95 \% \mathrm{Cl}: 0.92-0.97)$ following erythropoietin therapy. It was concluded that a higher haematocrit achieved either spontaneously or following erythropoietin therapy improved outcomes in patients undergoing 
dialysis. The findings in patients with low baseline haematocrit may be compatible with speculation that the association between haematocrit and morbidity/mortality is non-linear, perhaps $\mathrm{J}$ or $\mathrm{U}$ shaped. However, cautious interpretation is needed as end stage renal disease patients are not at low mortality risk.

\section{Association between elevated haematocrit and T2DM}

A further factor potentially linking haematocrit with mortality is its association with insulin resistance and impaired insulin secretion. This is important as adult onset TD is associated with T2DM with greater use of TTh in these patients and risk of further increased haematocrit levels. It is therefore, perhaps reasonable to consider T2DM patients as a subgroup when studying the clinical consequence of elevated haematocrit. Facchini et al. reported that increases in haematocrit and haemoglobin levels are associated with increased insulin resistance (by measuring steady-state plasma glucose levels after a 180-minute infusion of somatostatin, insulin and glucose), compensatory hyperinsulinaemia, elevated blood pressure, triglycerides and lower high density lipoprotein cholesterol values in 150 individuals [39]. When adjusted for all the above factors in a multiple regression analysis only insulin resistance and plasma insulin response to oral glucose remained associated with haematocrit and haemoglobin levels. In a prospective study of 7193 middle-aged men, Wannamethee et al. found an independent association between haematocrit and development of T2DM, independent of age, body mass index, smoking, physical activity, high density lipoprotein cholesterol, and systolic blood pressure [40]. T2DM was significantly higher in men with haematocrit levels $\geq 0.48$ compared with levels $<0.42$ (RR: 4.5; 95\% Cl: 2.5-6.3, adjusted for age and body mass index). Even after further adjustment for predictors of T2DM with which hematocrit is correlated, there 
remained a linear association with the risk of T2DM. The authors recommended that hematocrit, which is a major determinant of whole blood viscosity, should be added to the cluster of risk factors that link T2DM with CVD. As previously stated in the BLAST randomised controlled study $\mathrm{HbA} 1 \mathrm{c}$ levels were not associated with baseline haematocrit levels.

Clearly, monitoring haematocrit levels in men on TTh is essential [4]. An haematocrit level of 0.54 has been accepted as the level at which down-titration / discontinuation of TTh is recommended. Although studies hint at an association between haematocrit, CVD and all-cause mortality there is no consensus view.

It is reasonable to speculate that increased haematocrit levels result in altered blood flow characteristics that may lead to increased morbidity/mortality. Thus, it would be useful to characterise the blood flow changes that occur at different haematocrit levels in arteries varying in diameter. It is important that heterogeneity of disease pathogenesis is recognised since the adverse effects of TTh may only be seen in certain patient subgroups (Figure 2) [25]. Subgroups may be identified by broad phenotypes including age, diabetes and previous CVD as well as by those specific to adult onset TD and TTh; baseline testosterone and haematocrit, sexual health symptoms and other clinical consequences of hypotestosteronaemia. Subgroups may also be based on the extent of response to TTh or use of concomitant treatments such as antihypertensives, statins and phosphodiesterase 5-inhibitors. In this way the appropriateness of using a haematocrit level of 0.54 as the sole cut-off for clinical intervention can be assessed.

\section{Effects of haematocrit on blood flow characteristics}


A change in haematocrit is likely to affect blood flow due to increased viscosity leading to altered endothelial function and perfusion. This may, in part, explain the negative outcomes reported in some studies of TTh. We now focus on some theoretical considerations of the effects of haematocrit on blood flow. Blood viscosity is a key factor determining blood flow. Blood is a multi-component fluid comprising cellular elements (platelets, leucocytes, erythrocytes) and plasma. Blood behaves as a non-Newtonian fluid exhibiting shear-thinning behaviour as well as being viscoelastic and thixotropic [41]. While plasma alone was considered a Newtonian fluid for decades, more recent studies have shown that blood plasma has a noticeable viscoelastic behaviour [42, 43]. Erythrocytes, which are deformable, constitute the majority of the suspended elements in blood and have a propensity to aggregate at low shear rates, forming rouleaux.

As with most particle suspensions the viscosity of whole blood depends primarily on haematocrit, erythrocyte aggregation and deformability [44]. Blood viscosity is reported to increase exponentially [45] or quadratically [46] with haematocrit with the effect of haematocrit being more pronounced at lower shear rates due to its effect on erythrocyte aggregation contributing further to the shear thinning behaviour [47]. Wall shear is known to be associated with activating endothelial function. Piety et al found that increasing the haematocrit of erythrocyte suspensions in plasma in vitro from $20-60 \%$ resulted in a 3.5 fold increase in viscosity at a shear rate of $129 \mathrm{~s}^{-1}$ and a 17.5 fold increase at $0.3 \mathrm{~s}^{-1}$ [48]. Empirical correlations and various concentration dependent models have been developed to describe this effect of haematocrit on blood viscosity $[46,49,50]$. These will allow for improved of calculated wall shear stress in both micro and macrocirculation. 
It is well established that the vascular bed affects haematocrit distribution with haematocrit levels being lower in the microvasculature. When blood flows from a large vessel to a small-diameter one (less than about $0.3 \mathrm{~mm}$ ), the observed hematocrit level decrease is known as the Fåhræus effect [51]. The complex bifurcating microvascular architecture in conjunction with the particulate nature of blood gives rise to phenomena such as erythrocyte migration away from the wall and plasma skimming, resulting in higher flow rate branches receiving more cells and blood with a higher haematocrit [52]. This results in highly heterogeneous haematocrit distributions in the microcirculation that cause local variations in viscosity and flow resistance. This has been demonstrated in vivo [53] and in recent microfluidic studies of blood flow [54, 55].

In addition to the Fåhræus effect the particulate nature of blood is also responsible for phenomena such as leucocyte and platelet margination [56] where these smaller cells are observed to migrate towards the vessel wall. Increased haematocrit could lead to more interactions between erythrocytes and leucocytes or platelets promoting margination. Interestingly, Walton et al recently showed that elevated haematocrit in mice promoted arterial thrombosis perhaps due to rapid platelet accumulation within the thrombus [57].

Ageing and importantly T2DM in the context of TTh, can impair blood fluidity, altering tissue perfusion perhaps leading to functional deteriorations. It is well established that blood fluidity becomes impaired with age and erythrocyte life span [58, 59]. 
Disorders such as sickle cell disease [60-62] and diabetes [63-67] have been associated with reduced erythrocyte deformability.

Lower deformability of erythrocytes in T2DM has been associated with poor glycaemic control and microvascular complications such as diabetic retinopathy [68]. Erythrocytes in individuals with T2DM also undergo morphological changes with their shape deviating from the established biconcave disc to a more elongated shape [69]. These changes together with enhanced erythrocyte aggregation in T2DM can result in elevated blood viscosity which may be a factor in the pathogenesis of microvascular disease and non-flow limiting coronary artery disease [70, 71]. It is possible this risk is exacerbated by TTh associated increase in haematocrit.

Changes in macrovascular flow characteristics that may be associated with increased haematocrit are also potentially important. Both end diastolic and peak systolic velocities have been associated with atherogenesis [72-76]. Our research group found that lower peak systolic velocity, based on ultrasound measurements in the carotid artery, was associated with coronary heart disease [72].

\section{Optimal haematocrit}

Salazar-Vazquez et al [77] suggested that the treatment of diabetes should target the maintenance of an optimal haematocrit in order to lower cardiovascular risk, prompting the question what is the ideal haematocrit? Clinical guidelines use a value $<0.54$ based on a population distribution and not physiological evaluation. Increased haematocrit should theoretically increase tissue oxygenation as oxygen content varies linearly with haematocrit. However, it also increases blood viscosity in an 
exponential function reducing blood flow; hence an ideal haematocrit should exist that optimises tissue oxygenation and flow performance. A recent in vitro study concluded that the optimum haematocrit is different for large and small vessels, attributed to the difference in driving pressures and hence perfusion rates [48]. Many cardiovascular conditions result in lower blood flow rates either in systemic circulation or locally which might result in the optimal haematocrit being lower than the physiological one. This could be due to rheological changes brought about by impaired erythrocyte deformability or increased erythrocyte aggregation, endothelial dysfunction or decreased cardiac output [45]. An increase in haematocrit will increase whole blood viscosity which in turn will require a high blood pressure to maintain flow. Whilst the required increase in blood pressure can be quantified easily in vitro, the situation is more complex in vivo. Factors such as altered vessel elasticity, endothelial function and release of vasodilators (e.g. nitric oxide) may influence the compensatory mechanisms. The above makes a case for individuals with T2DM to be considered as a subgroup since the efficiency of these factors may differ from that in health. In sickle cell anaemia, for example, the optimum haematocrit for transfusion has been set below 0.30 [78]. This implies that the optimum haematocrit in disease is subgroup specific and depends on the many factors impacting blood rheology.

Therapeutic phlebotomy is the mainstay of controlling haematocrit in polycythaemia vera $(\mathrm{PV})$. Some experts suggest haematocrit targets of $<0.45$ in men and $<0.42$ percent in women [79-82]. A prospective trial randomly assigned 365 adults with PV to more intensive treatment (target haematocrit, $<0.45$ ) versus less intensive treatment (target haematocrit: $0.45-0.50$ percent); control of haematocrit achieved 
by phlebotomy, hydroxyurea, or both. After a median follow-up of 31 months, compared with the more intensive therapy group, the less intensive therapy was associated with shorter time to death from CVD or major thrombotic events (HR: 3.9, $95 \% \mathrm{Cl}: 1.5-10.5]$; with events reported in $10 \%$ of the less intensive therapy group and $3 \%$ in the more intensive treatment group [80].

\section{Conclusion}

Although TTh use has increased with most studies demonstrating benefit, doubts of its safety based on a few controversial reports of increased CVD remain. We have seen that increased haematocrit is the commonest adverse effect of TTh and guidelines regarding action thresholds are based on a population derived level of 0.54. Longitudinal studies suggest that haematocrit influences CVD morbidity and mortality, although the association may not be linear. It is clear that further studies are required and we propose that in addition to clinical studies with hard and surrogate end-points, changes in blood flow characteristics should be evaluated across macro- and micro-circulatory vascular beds.

Advanced computational tools are required to understand the particulate nature of blood in the microcirculation taking into account the impact of increased haematocrit and altered erythrocyte properties. Although this has been carried out in some pathologies (sickle cell anaemia [83], malaria [84]) only simple vascular geometries rather than networks were considered. Microfluidics has allowed microscale blood flow characteristics to be probed allowing cell and flow distribution to be resolved and phenomena such as erythrocyte aggregation and deformability on those to be 
studied in detail $[52,53]$. Thus, concurrent studies of clinical outcomes and evaluation of flow changes following haematocrit change during TTh in different patient groups will allow management guidance based on evidence that allows for patient heterogeneity.

\section{References}

1. Harman SM, Metter EJ, Tobin JD, Pearson J, Blackman MR. Longitudinal effects of aging on serum total and free testosterone levels in healthy men. Baltimore Longitudinal Study of Aging. J Clin Endocrinol Metab 2001; 86: 724-731.

2. Araujo AB, Esche GR, Kupelian V, O'Donnell AB, Travison TG, Williams RE, et al. Prevalence of symptomatic androgen deficiency in men. J Clin Endocrinol Metab 2007; 92: 4241-4247.

3. Livingston M, Kalansooriya A, Hartland AJ, Ramachandran S, Heald A. Serum testosterone levels in male hypogonadism: Why and when to check A review. Int J Clin Pract. 2017; 71:e12995.

4. Hackett G, Kirby M, Edwards D, Jones TH, Wylie K, Ossei-Gerning N et al. British Society for Sexual Medicine guidelines on adult testosterone deficiency, with statements for UK practice. J Sex Med 2017; 14: 1504-1523.

5. Kapoor D, Aldred H, Clark S, Channer KS, Jones TH. Clinical and biochemical assessment of hypogonadism in men with type 2 diabetes: correlations with bioavailable testosterone and visceral adiposity. Diabetes Care 2007; 30: 911-917.

6. Hackett G, Cole N, Deshpande A, Popple M, Kennedy D,Wilkinson P. Biochemical hypodonadism and type 2 diabetes in primary care. The British Journal of Diabetes \& Vascular Disease 2009; 9: 226-231. 
7. Holmboe SA, Jensen TK, Linneberg A, Scheike T, Thuesen BH, Skakkebaek NE et al. Low Testosterone: A Risk Marker Rather Than a Risk Factor for Type 2 Diabetes. J Clin Endocrinol Metab 2016; 101: 3180-3190.

8. Pye SR, Huhtaniemi JD, Finn DM, Lee TW, O'Neill AT, Tajar A et al. Lateonset hypogonadism and mortality in aging men. J Clin Endocrinol Metab 2014; 99: 1357-1366.

9. Shores MM, Smith NL, Forsberg CW, Anawalt BD, Matsumoto AM. Testosterone treatment and mortality in men with low testosterone levels. J Clin Endocrinol Metab 2012; 97: 2050-2058.

10. Muraleedaran V, Marsh H, Kapoor D, Channer KS, Jones TH. Testosterone deficiency is associated with increased risk of mortality and testosterone replacement improves survival in men with type 2 diabetes. Eur $\mathrm{J}$ Endocrinol 2013; 169: 725-733.

11. Hackett G, Heald AH, Sinclair A, Jones PW, Strange RC, Ramachandran S. Serum testosterone, testosterone replacement therapy and all-cause mortality in men with type 2 diabetes: retrospective consideration of the impact of PDE5 inhibitors and statins. Int J Clin Pract 2016; 70: 244-253.

12. Hackett G, Jones PW, Strange RC, Ramachandran S. Statin, testosterone and phosphodiesterase 5-inhibitor treatments and age related mortality in diabetes. World J Diabetes 2017; 8: 104-111.

13. Hackett GI, Cole N, Mulay A, Strange RC, Ramachandran S. Long-term Testosterone Therapy in Type 2 Diabetes is associated with reduced Mortality without improvement in conventional cardiovascular risk factors. BJU Int 2018 (in press: Epub ahead of print; https://www.ncbi.nlm.nih.gov/pubmed/?term=Long- 
term+Testosterone+Therapy+in+Type+2+Diabetes+is+associated+with+redu ced+Mortality+without+improvement+in+conventional+cardiovascular+risk+fa ctors - accessed 02/01/2019)

14. Snyder PJ, Bhasin S, Cunningham GR, Matsumoto AM, Stephens-Shields AJ, Cauley JA et al. Effects of testosterone treatment in older men. $\mathrm{N}$ Engl J Med 2016; 374: 611-624.

15. Hackett G, Cole N, Saghir A, Jones P, Strange RC, Ramachandran S. Testosterone Undecanoate improves sexual function in men with type 2 diabetes and severe Hypogonadism: results from a 30 week randomised placebo controlled study. BJU Int 2016; 118: 804-813.

16. Hackett G, Cole N, Saghir A, Jones P, Strange RC, Ramachandran S. Testosterone replacement therapy: improved sexual desire and erectile function in men with type 2 diabetes following a 30-week randomized placebocontrolled study. Andrology 2017; 5: 905-913.

17. Hackett GI, Cole N, Mulay A, Strange RC, Ramachandran S. Long term testosterone therapy in type 2 diabetes is associated with decreasing waist circumference and improving erectile dysfunction. World J Mens Health 2018 (in press: Epub ahead of print; https://www.ncbi.nlm.nih.gov/pubmed/?term=Long+term+testosterone+therap

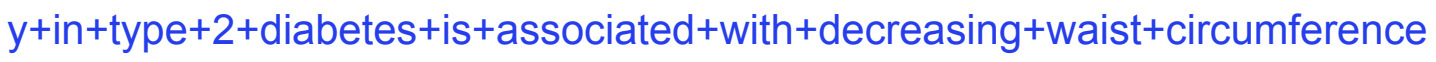
+and+improving+erectile+dysfunction - accessed 02/01/2019).

18. Miner M, Morgentaler A, Kheira M, Traish AM. The state of testosterone therapy since the FDA's 2015 labelling changes: indications and cardiovascular risk. Clin Endocrinol (Oxf) 2018; 89: 3-10. 
19. Morgentaler A, Zitzmann M, Traish AM, Fox AW, Hugh Jones T, Maggi M et al. Fundamental Concepts Regarding Testosterone Deficiency and Treatment: International Expert Consensus Resolutions. Mayo Clin Proc. $2016 ; 91: 881-896$

20. Vigen R, O'Donnell CI, Barón AE, Grunwald GK, Maddox TM, Bradley SM et al. Association of testosterone therapy with mortality, myocardial infarction, and stroke in men with low testosterone levels. JAMA 2013; 310: 1829-1836.

21. Finkle WD, Greenland S, Ridgeway GK, Adams JL, Frasco MA, Cook MB et al. Increased risk of non-fatal myocardial infarction following testosterone therapy prescription in men. PLoS One 2014; 9: e85805.

22. Andersson DP, Trolle Lagerros Y, Grotta A, Bellocco R, Lehtihet M, Holtzmann M J. Association between treatment for erectile dysfunction and death or cardiovascular outcomes after myocardial infarction. Heart 2017; 103: $1264-1270$.

23. Anderson SG, Hutchings DC, Woodward M. Rahimi K, Rutter MK, Kirby M et al. Phosphodiesterase type-5 inhibitor use in type 2 diabetes is associated with a reduction in all-cause mortality. Heart 2016; 102: 1750-1756.

24. Basaria S, Coviello AD, Travison TG, Storer TW, Farwell WR, Jette AM et al. Adverse events associated with testosterone administration. N Engl J Med 2010; 363: 109-122.

25. Ramachandran S, König CS, Hackett G, Livingston M, Strange RC. Managing clinical heterogeneity: An argument for benefit based action limits. Journal of Medical Diagnostics and Therapy 2018; 1: 034701.

26. Calof O, Singh AB, Lee ML, Urban RJ, Kenny AM, Tenover JL et al. Adverse events associated with testosterone supplementation of older men: a meta- 
analysis of randomized, placebo-controlled trials. J Gerontol A Med Sci 2005; $60: 1451-1457$.

27. Bhasin S, Cunningham GR, Hayes FJ, Matsumoto AM, Snyder PJ, Swerdloff RS et al. Testosterone therapy in men with androgen deficiency syndromes: an Endocrine Society clinical practice guideline. J Clin Endocrinol Metab. 2010; 95: 2536-2559.

28. Ohlander SJ, Varghese B, Pastuszak AW. Erythrocytosis Following Testosterone Therapy. Sex Med Rev 2018; 6: 77-85.

29. Hackett G, Cole N, Bhartia M, Kennedy D, Raju J, and Wilkinson P. Testosterone replacement therapy with long-acting Testosterone Undecanoate improves sexual function and quality-of-life parameters vs. placebo in a population of men with type 2 diabetes. J Sex Med 2013; 10 : $1612-1627$.

30. Ip FF, di Pierro I, Brown R, Cunningham I, Handelsman DJ, Liu PY. Trough serum testosterone predicts the development of polycythemia in hypogonadal men treated for up to 21 years with subcutaneous testosterone pellets. Eur $\mathrm{J}$ Endocrinol 2010; 162: 385-390.

31. Coviello AD, Kaplan B, Lakshman KM, Chen T, Singh AB, Bhasin S. Effects of Graded Doses of Testosterone on Erythropoiesis in Healthy Young and Older Men. J Clin Endocrinol Metab 2008; 93: 914 -919.

32. Bachman E, Travison TG, Basaria S, Davda MN, Guo W, Li M et al. Testosterone induces erythrocytosis via increased erythropoietin and suppressed hepcidin: evidence for a new erythropoietin/hemoglobin set point. J Gerontol A Biol Sci Med Sci 2014; 69: 725-735. 
33. Danesh J, Collins R, Peto R, Lowe GDO. Haematocrit, viscosity, erythrocyte sedimentation rate: meta-analyses of prospective studies of coronary heart disease. Eur Heart J 2000; 21: 515-520.

34. Lassale C, Curtis A, Abete I, van der Schouw YT, Verschuren WMM, Lu Y et al. Elements of the complete blood count associated with cardiovascular disease incidence: Findings from the EPIC-NL cohort study. Sci Rep. 2018; 8:3290.

35. Peters SA, Woodward M, Rumley A, Tunstall-Pedoe HD, Lowe GD. Plasma and blood viscosity in the prediction of cardiovascular disease and mortality in the Scottish Heart Health Extended Cohort Study. Eur J Prev Cardiol 2016; 24: $161-167$.

36. Gagnon DR, Zhang TJ, Brand FN, Kannel WB. Hematocrit and the risk of cardiovascular disease--the Framingham study: a 34-year followup. Am Heart J 1994; 127: 674-682.

37. Boffetta P, Islami F, Vedanthan R, Pourshams A, Kamangar F,Khademi H et al. A U-shaped relationship between haematocrit and mortality in a large prospective cohort study. Int J Epidemiol 2013; 42: 601-615.

38. Locatelli F, Conte F, Marcelli D. The impact of haematocrit levels and erythropoietin treatment on overall and cardiovascular mortality and morbidity-the experience of the Lombardy Dialysis Registry. Nephrol Dial Transplant. 1998; 13: 1642-1644.

39. Facchini FS, Carantoni M, Jeppesen J, Reaven GM. Hematocrit and hemoglobin are independently related to insulin resistance and compensatory hyperinsulinemia in healthy, non-obese men and women. Metabolism 1998; 47: 831-835. 
40. Wannamethee SG, Perry IJ, Shaper AG. Hematocrit and risk of NIDDM. Diabetes 1996; 45: 576-579.

41. Antonova N. On some mathematical models in hemorheology. Biotechnology \& Biotechnological. Equipment 2012; 26: 3286-3291.

42. Varchanis S, Dimakopoulos Y, Wagnerb C, Tsamopoulosa J. How viscoelastic is human blood plasma? Soft Matter 2018; 14: 4238-4251.

43. Brust M, Schaefer C, Doerr R, Pan L, Garcia M, Arratia PE et al. Rheology of Human Blood Plasma: Viscoelastic Versus Newtonian Behavior. Phys Rev Lett 2013; 110: 078305.

44. Pasquini G, Albanese B, Manescalchi PG, Morini R. Relation of blood viscosity, plasma viscosity and haematocrit. Ric Clin Lab 1983; 13 Suppl 3: $327-331$.

45. Reinhart WH. The optimum hematocrit. Clin Hemorheol Microcirc 2016; 64: $575-585$.

46. Apostolidis AJ, Beris AN. Modeling of the blood rheology in steady-state shear flows. J. Rheol 2014; 58: 607-633.

47. Sousa PC, Pinho FT, Alves MA, Oliveira MSN. A review of hemorheology: Measuring techniques and recent advances. Korea-Australia Rheology Journal 2016; 28:1-22.

48. Piety NZ, Reinhart WH, Stutz J, Shevkoplyas SS. Optimal hematocrit in an artificial microvascular network. Transfusion 2017; 57; 2257-2266.

49. Picart C, Piau JM, Galliard H, Carpentier P. Blood yield stress and its Hematocrit Dependence. J Rheol 1998; 42:1-12.

50. Hund SJ, Kameneva MV, Antaki JF. A quasi-mechanistic mathematical representation for blood viscosity. Fluids 2017; 2: 10. 
51. Secomb TW, Pries AR. Blood viscosity in microvessels: experiment and theory. C R Phys 2013; 14: 470-478.

52. Secomb TW. Blood Flow in the Microcirculation. Annual Review of fluid Mechanics 2017; 49: 443-461.

53. Pries AR, Ley K, Claassen M, Gaehtgens P. 1989. Red cell distribution at microvascular bifurcations. Microvasc Res; 38: 81-101.

54. Sherwood J, Holman D, Kaliviotis E, Balabani S. Spatial distributions of red blood cells significantly alter local haemodynamics. PLoS One 2014; 9: e100473.

55. Kaliviotis E, Sherwood JM, Balabani S. Local viscosity distribution in bifurcating microfluidic blood flows. Physics of Fluids 2018; 30: 030706.

56. Chang H-Y, Yazdani A, Li X, Douglas KAA, Mantzoros CS, Karniadakis GE. Quantifying Platelet Margination in Diabetic Blood Flow. Biophysical Journal 2018; 115: 1371-1382.

57. Walton BL, Lehmann M, Skorczewski T, Holle LA, Beckman JD, Cribb JA et al. Elevated hematocrit enhances platelet accumulation following vascular injury. Blood 2017; 129: 2537-2546.

58. Huang YX, Wu ZJ, Mehrishi J, Huang BT, Chen XY, Zheng XJ et al. Human red blood cell aging: correlative changes in surface charge and cell properties. J Cell Mol Med 2011; 15: 2634-2642.

59. Simmonds MJ, Meiselman HJ, Baskurt OK. Blood rheology and aging. J Geriatr Cardiol 2013; 10: 291-301.

60. Alapan Y, Little J, Gurkan UA. Heterogeneous Red Blood Cell Adhesion and Deformability in Sickle Cell Disease. Sci Rep 2014; 4: 7173. 
61. Alapan Y, Matsuyama Y, Little J, Gurkan UA. Dynamic deformability of sickle red blood cells in microphysiological flow. Technology (Singap World Sci) 2016; 4: 71-79.

62. Dufu K, Patel M, Oksenberg D, Cabrales P. GBT440 improves red blood cell deformability and reduces viscosity of sickle cell blood under deoxygenated conditions. Clin Hemorheol Microcirc 2018; 70: 95-105.

63. Vague $P$, Juhan I. Red cell deformability, platelet aggregation, and insulin action. Diabetes 1983; 32 Suppl 2:88-91.

64. Sabo A, Jakovljević V, Stanulović M, Lepsanović L, Pejin D. Red blood cell deformability in diabetes mellitus: effect of phytomenadione. Int J Clin Pharmacol Ther Toxicol 1993; 31: 1-5.

65. Keymel S, Heiss C, Kleinbongard P, Kelm M, Lauer T. Impaired red blood cell deformability in patients with coronary artery disease and diabetes mellitus. Horm Metab Res 2011; 43: 760-765.

66. Agrawal R, Smart T, Nobre-Cardoso J, Richards C, Bhatnagar R, Tufail A et al. Assessment of red blood cell deformability in type 2 diabetes mellitus and diabetic retinopathy by dual optical tweezers stretching technique. Sci Rep. 2016; 6: 15873.

67. Fornal M, Lekka M, Pyka-Fościak G, Lebed K, Grodzicki T, Wizner B et al. Erythrocyte stiffness in diabetes mellitus studied with atomic force microscope Clin Hemorheol Microcirculation 2006; 35: 273-276.

68. Moon JS, Kim JH, Kim JH, Park IR, Lee JH, Kim HJ et al. Impaired RBC deformability is associated with diabetic retinopathy in patients with type 2 diabetes. Diabetes Metab 2016; 42:448-452. 
69. Pretorius E, Kell DB. Diagnostic morphology: biophysical indicators for irondriven inflammatory diseases. Integr Biol (Camb) 2014; 6: 486-510.

70. Cho YI, Mooney MP, Cho DJ. Hemorheological Disorders in Diabetes Mellitus. J Diabetes Sci Technol 2008; 2: 1130-1138.

71. Lin T, Rechenmacher S, Rasool S, Varadarajan P, Pai RG. Reduced Survival in Patients with "Coronary Microvascular Disease" Int J Angiol 2012; 21: 8994.

72. König CS, Atherton M, Cavazutti M, Ramachandran S, Gomm C, Strange RC et al. A pilot study to assess peak systolic velocity as a possible marker of atherosclerotic burden using ultrasound. Artery Research 2017; 20: 76.

73. Chuang SY, Bai CH, Cheng HM, Chen JR, Yeh WT, Hsu PFet al. Common carotid artery end-diastolic velocity is independently associated with future cardiovascular events. Eur J Prev Cardiol 2016; 23:116-124.

74. El-Sakka Al, Morsy AM, Fagih BI, Nassar AH. Coronary artery risk factors in patients with erectile dysfunction. J Urol 2004; 172: 251-254.

75. Gupta N, Herati A, Gilbert BR. Penile Doppler ultrasound predicting cardiovascular disease in men with erectile dysfunction. Curr Urol Rep 2015; 16: 16 .

76. Westholm C, Johnson J, Sahlen A, Winter R, Jernberg T. Peak systolic velocity using color-coded tissue Doppler imaging, a strong and independent predictor of outcome in acute coronary syndrome patients. Cardiovasc ultrasound 2013; 11: 9.

77. Salazar-Vasquez BY, Intaglietta M, Rodriguez-Moran M, Guerrero-Romero F. Blood pressure and haematocrit in diabetes and the role of endothelial 
responses in the variability of blood viscosity. Diabetes Care 2006; 29: 15231528.

78. Wun T, Hassell K. Best practices for transfusion for patients with sickle cell disease. Hematol Rev 2009; 1: e22.

79. Barbui T, Barosi G, Birgegard G, Cervantes F, Finazzi G, Griesshammer M et al. Philadelphia-negative classical myeloproliferative neoplasms: critical concepts and management recommendations from European LeukemiaNet. J Clin Oncol, 2011. 29: 761-770.

80. Marchioli R, Finazzi G, Specchia G, Cacciola R, Cavazzina R, Cilloni D et al. Cardiovascular events and intensity of treatment in polycythemia vera. $\mathrm{N} \mathrm{Engl}$ J Med 2013; 368: 22-33.

81. Finazzi G, Barbui T. How I treat patients with polycythemia vera. Blood 2007; 109: 5104-5111.

82. Tefferi A, Spivak JL. Polycythemia vera: scientific advances and current practice. Semin Hematol 2005; 42: 206-220.

83. Li X, Li H, Chang HY, Lykotrafitis G, Em Karniadakis G. Computational Biomechanics of Human Red Blood Cells in Hematological Disorders. J Biomech Eng 2017; 139: 0210081-02100813.

84. Fedosov DA, Pan W, Caswell B, Gompper G, Karniadakis GE. Predicting human blood viscosity in silico. Proc Natl Acad Sci USA 2011: 108: 1177211777. 
Figure 1: Change in haematocrit following 30 weeks of treatment in the placebo and TTh groups (BLAST study of men with T2DM).

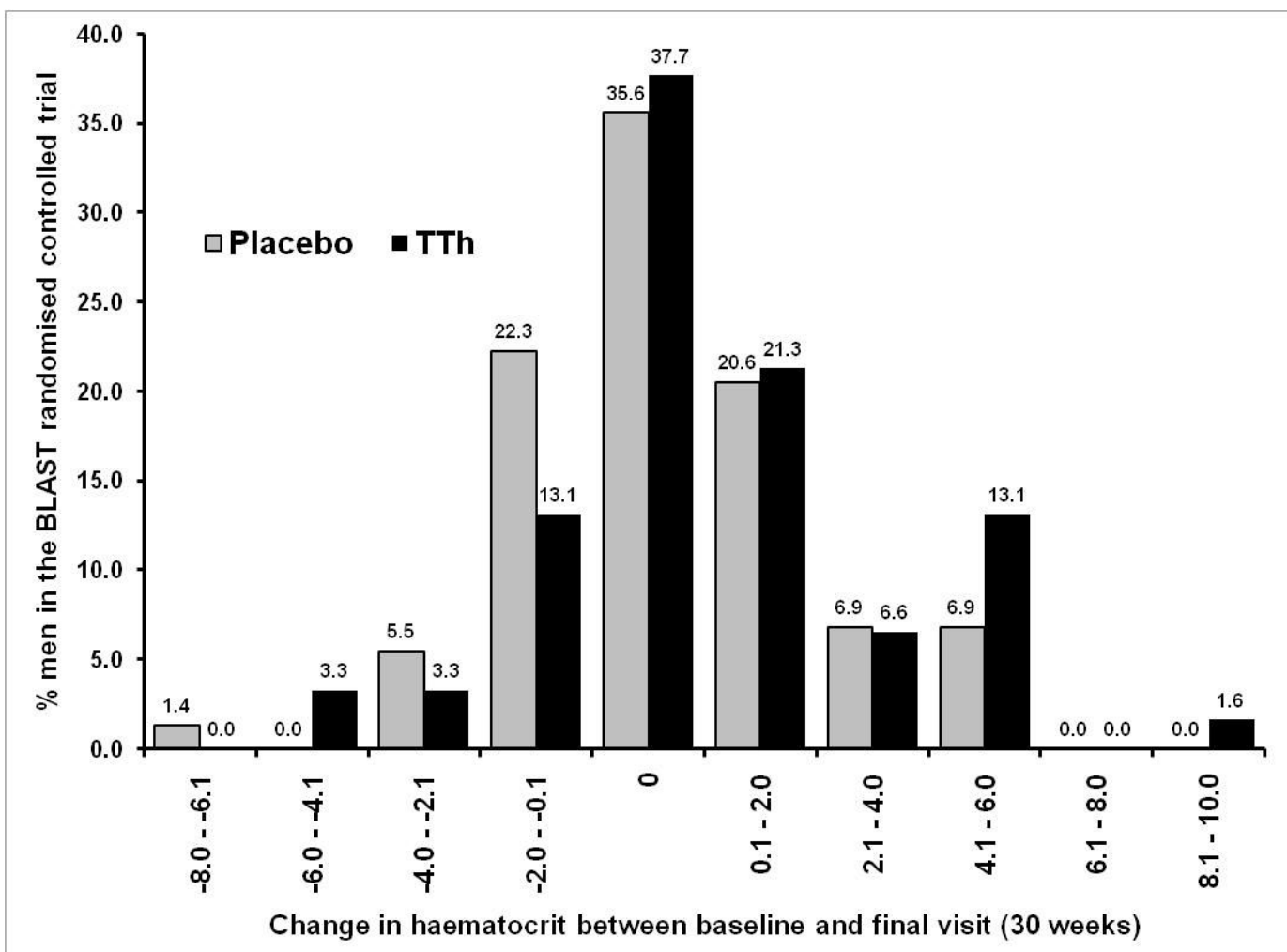


Figure 2: A diagrammatic scheme of the importance of heterogeneity in complex diseases.

This figure was previously published in: Ramachandran S, König CS, Hackett G, Livingston M, Strange RC. Managing clinical heterogeneity: An argument for benefit based action limits. Journal of Medical Diagnostics and Therapy 2018; 1: 034701

(permission to use the figure was obtained from the journal)

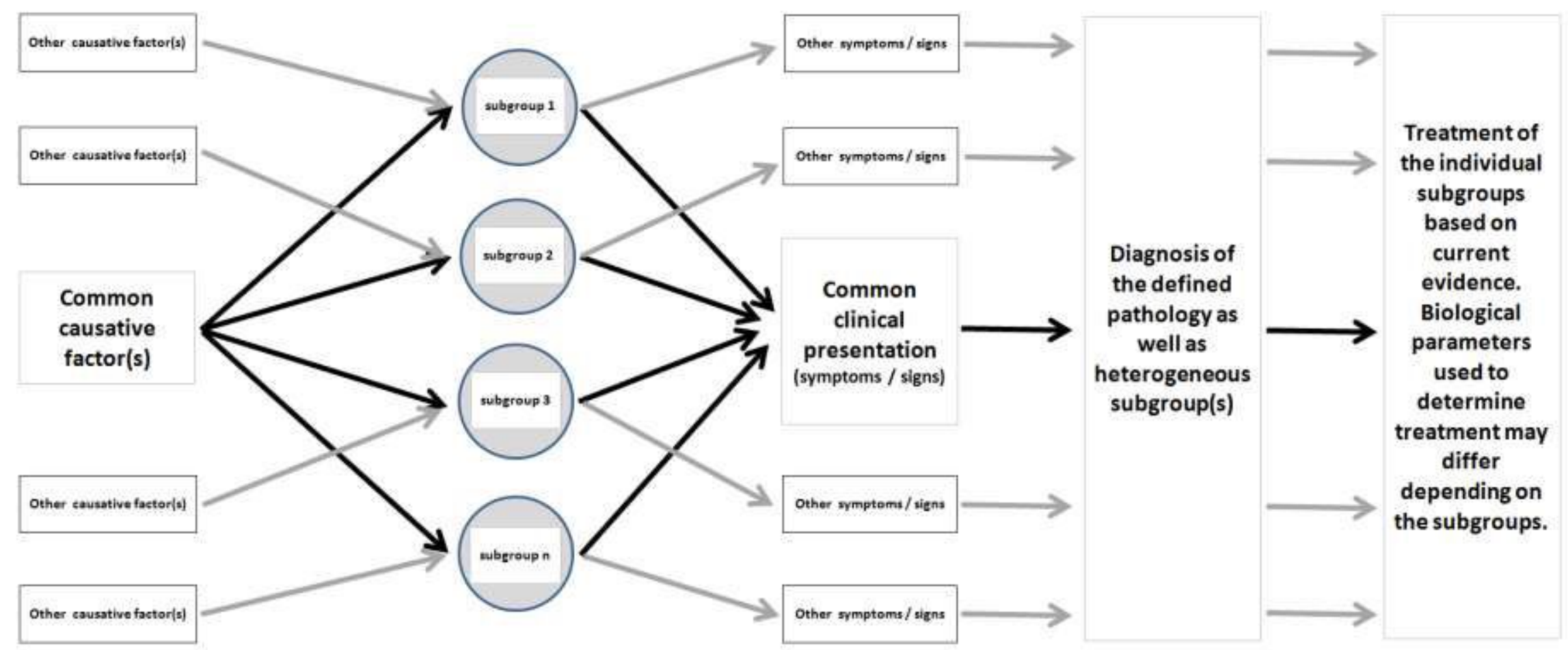




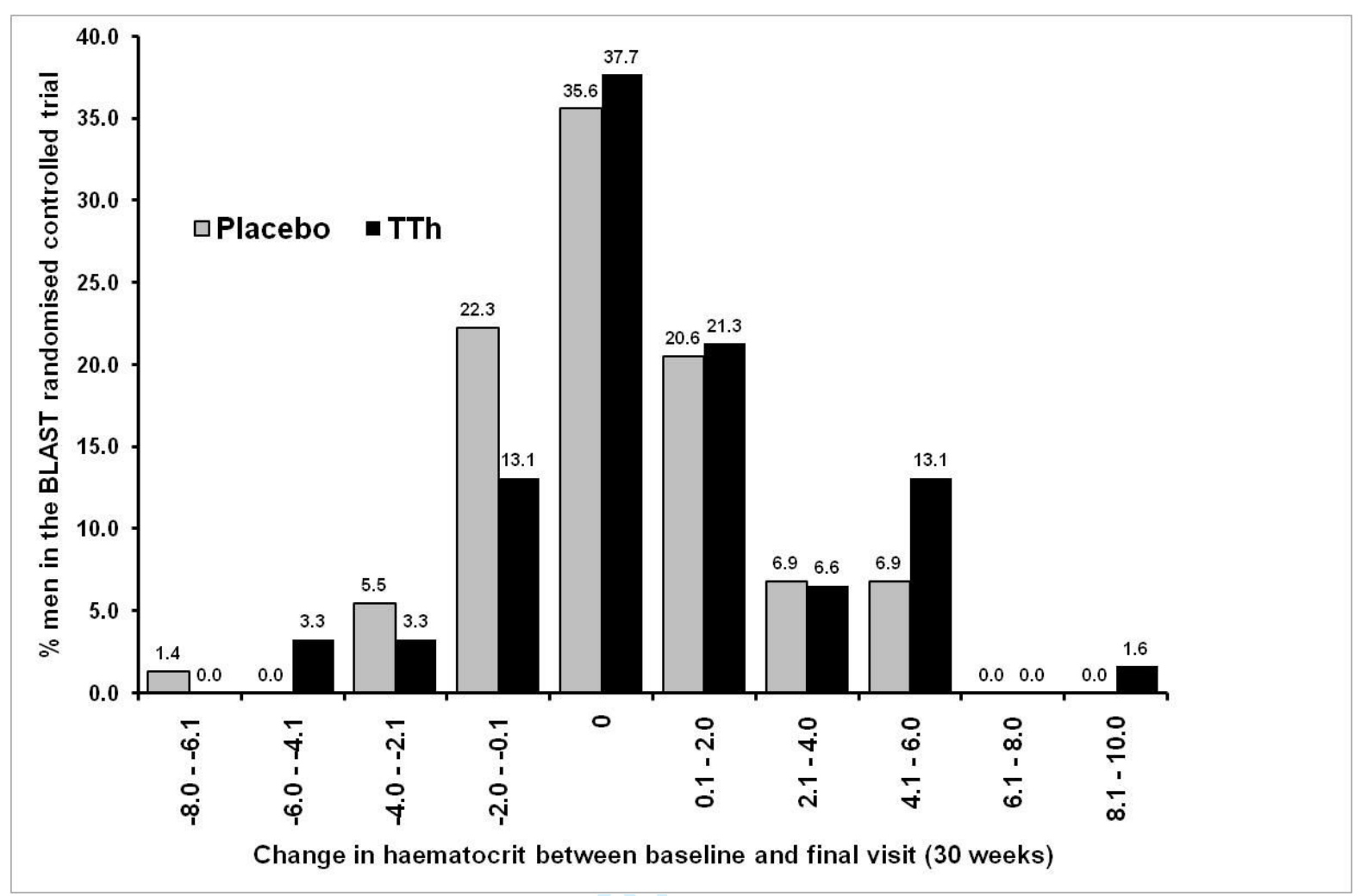




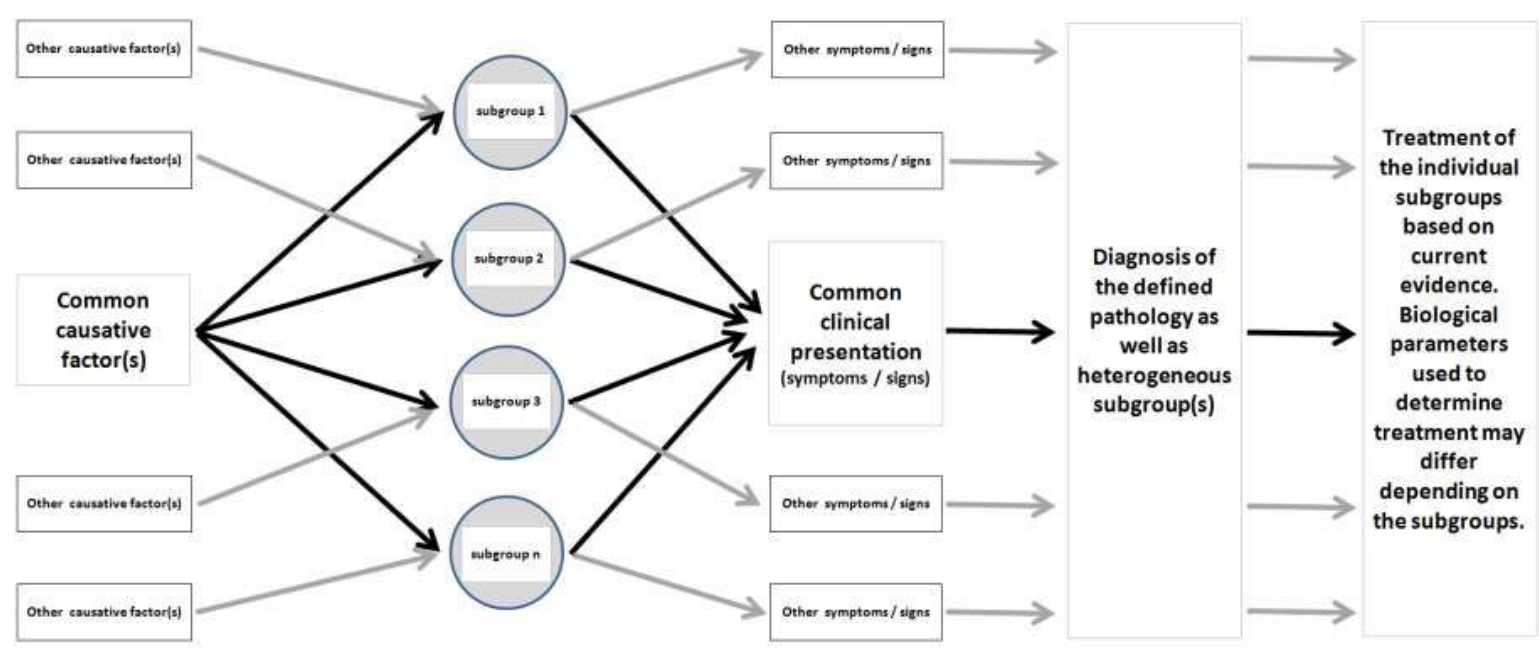

